EDINBURGH GEOLOGICAL SOCIETY.

VI.--Igneous Intrusive Phenomena at Upper Whitfield, near Macbiehill; and at Ravelrig and Kaimes Hill Quarries, Balerno. By T. Cuthbert DAy, F.C.S., F.R.S.E. (With Plates III-VI.)

(Read 20th December, 1916.)

WHEN describing a peculiar form of metasomatism in basalt at Upper Whitfield, at the meeting of the Edinburgh Geological Society, in January, 1916, I stated that the relationship of the mass of the basalt to the sedimentary deposits was not clear. The igneous rock is very vesicular in places, and the microscopic section displayed pronounced flow structure, which indicated that perhaps a lava was being dealt with, but no contacts with the sedimentary rocks had been found. I considered the matter worthy of investigation, and instituted a stricter search, which resulted in the discovery of two contacts, an upper and a lower, which presented some peculiar features of considerable interest, besides establishing the undoubted intrusive nature of the basalt itself.

One, an inferior contact, occurs at a section on the Cairn Burn, a little way below the Water Works buildings at Upper Whitfield. The basalt occupies about 6 yards on the left bank of the stream and has rather the appearance of a dyke. Its connection with the main intrusion is not obvious, but it is probably a tongue, and, moreover, displays the same character in a microscopic section. The basalt is much decomposed by exfoliation, and below it, just on the margin of the stream and in contact with the decomposed and exfoliated basalt, are seen the sedimentary rocks, much hardened by igneous contact. They consist of quartzites and marmorised dolomite. The sedimentary rocks in the immediate vicinity are very soft sandstones cemented by silica, with lenticular bands containing numerous fragments of chert. I have not found any dolomite or limestone among them except at the point of contact with the basalt; and can only suggest that at this particular place there happened to be a small deposit of dolomitic limestone in the sandstones. The dolomite contains grains of sedimentary quartz. The very soft sandstones have been converted into hard quartzites in the usual way.

The soft exfoliated basalt near the point of contact was found to contain many fragments of the sedimentary rocks, of various sizes, subangular in outline, and evidently removed and embedded in the igneous magna at the time of intrusion. Adhering to these fragments there is still the remains of a skin of harder 
IGNEOUS INTRUSIVE PHENOMENA AT UPPER WHITFIELD. 15

basalt, while tongues are also seen penetrating their mass. Some fragments of chert were involved, which were apparently first fractured by the heat, the fine cracks being subsequently filled by the molten intrusive basalt. In many cases these little veins of basalt can be readily recognised as such, though much decomposed (Plate III, Fig. 1). Replacement by calcite has taken place largely, but even then sufficient decomposed remains of the basalt are present to show that the latter was once the filling material. An interesting point may be noticed in this microsection: everywhere, in the immediate neighbourhood of the little basalt veins, the chert has been rendered more transparent, possibly by the initial heat of the intrusive basalt.

The marmorised dolomite at the point of contact contains a certain quantity of cherty material. The two together have been so acted upon by the heat of intrusion that they have become blended into a mass, the dolomite occurring as spherulites embedded in the chert (Plate III, Fig. 2). An analysis of the dolomitic part of this rock gave :-

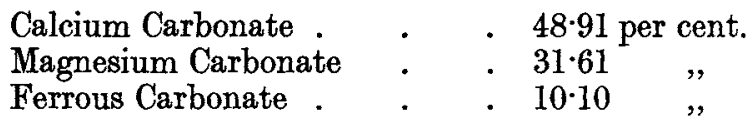

besides other constituents as $\mathrm{SiO}_{2}$, etc. ; which represents a dolomite containing 10 per cent. of siderite.

The cherty material in the rock furnished, on complete analysis :-

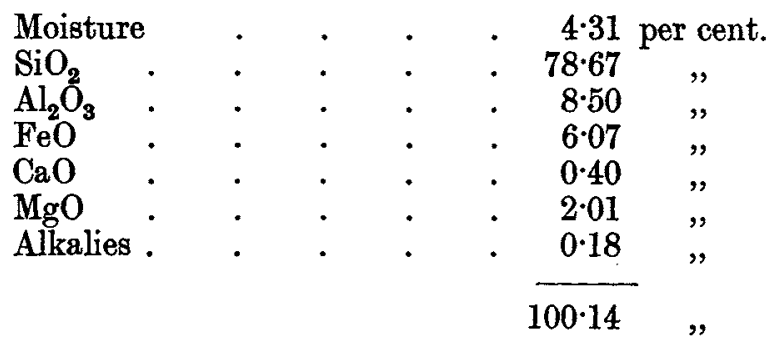

The analysis shows that the original chert had been modified by the absorption of iron and magnesia. Where the chert alone had been invaded by the basalt no magnesia, and only a small amount of iron was found.

Another, an upper, contact of sedimentary rocks with the Upper Whitfield basalt was found at a point 52 yards above the bridge at the waterworks. The exposure of the basalt can be readily seen in the stream both above and below the bridge. Above the bridge it can be traced for a few yards; it is then apparently lost, but a close examination of the bed of the stream 
shows that the rock over which the water flows is a very soft, green decomposed basalt, which can be traced for most part of the 52 yards, though much obscured in places by boulders and pebbles. In this decomposed basalt there has been a deposit of crystalline dolomitic calcite with a considerable proportion of siderite. There is no evidence to show how this deposit originated; it occurs in considerable masses and has grown at the expense of the basalt, which it has metasomatised: almost all stages of the process can be seen in hand specimens. The original microstructure of the basalt is to a considerable extent preserved (Plate IV, Fig. 1). This curious crystalline deposit furnished on partial analysis :-

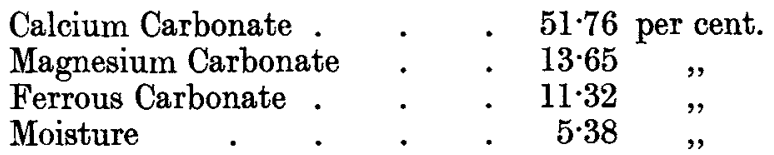

As previously mentioned, an upper contact of the basalt with the sedimentary rocks is met with at a point 52 yards above the bridge. A band of sandstone, hardened into quartzite, about 1 foot thick, crosses the stream, dipping slightly to the east (Plate IV, Fig. 2). It seemed to be a contact quartzite, but an attempt to ascertain what kind of rock was in contact with it below failed, owing to the fact that it was completely decayed and washed away by the stream. On detaching a portion, the under surface appeared to be moulded and puckered as if from contact with an igneous rock now removed. In order to test this, the turf on the bank of the burn was removed and one or two flags of the quartzite lifted. Underneath it was seen a soft green coloured rock, which looked somewhat like a decomposed basalt, but it had also a sandy appearance. Enclosed in this soft material were considerable lumps of quartzite, apparently detached from the roof above and sunk into the invading magna. The sandy-looking greenish rock proved to be a basalt charged with sand grains caused by invasion and disintegration of a soft sandstone deposit. A microsection of this peculiar rock appears to establish this fact (Plate V, Fig. 1).

In Plate V, Fig. 2, are shown the sand grains separated from the basalt, with their etched surfaces.

It will now be noticed that, at both the contacts described, portions of the sedimentary rocks have been detached and engulfed in the basalt. These phenomena are similar to what is seen on a much larger scale at Cheese Bay near Gullane, in connection with a basalt of a similar type.

Near Balerno, in the Ravelrig and Kaimes Hill quarries, some interesting cases of contacts with the olivine dolerite of the 


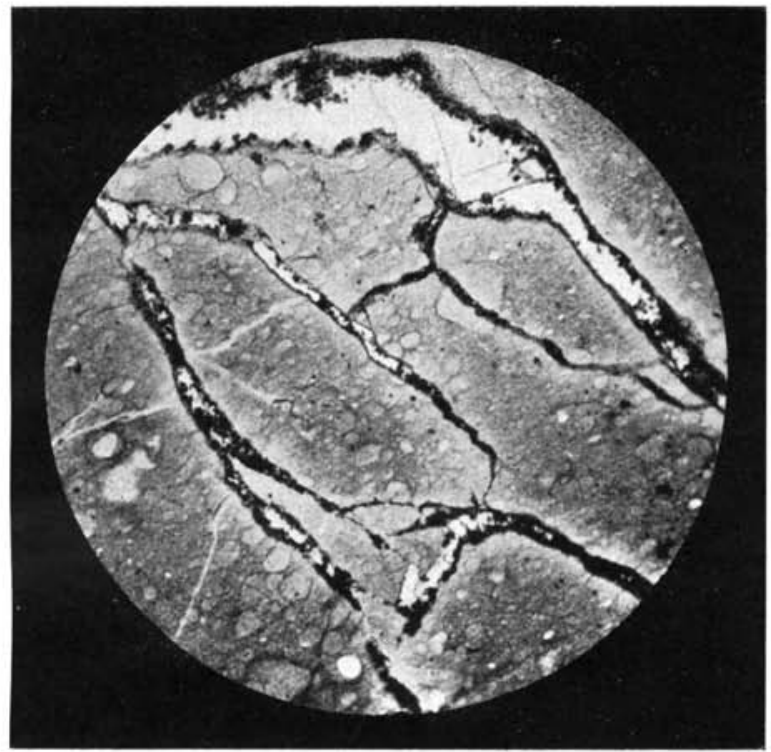

liti. 1.

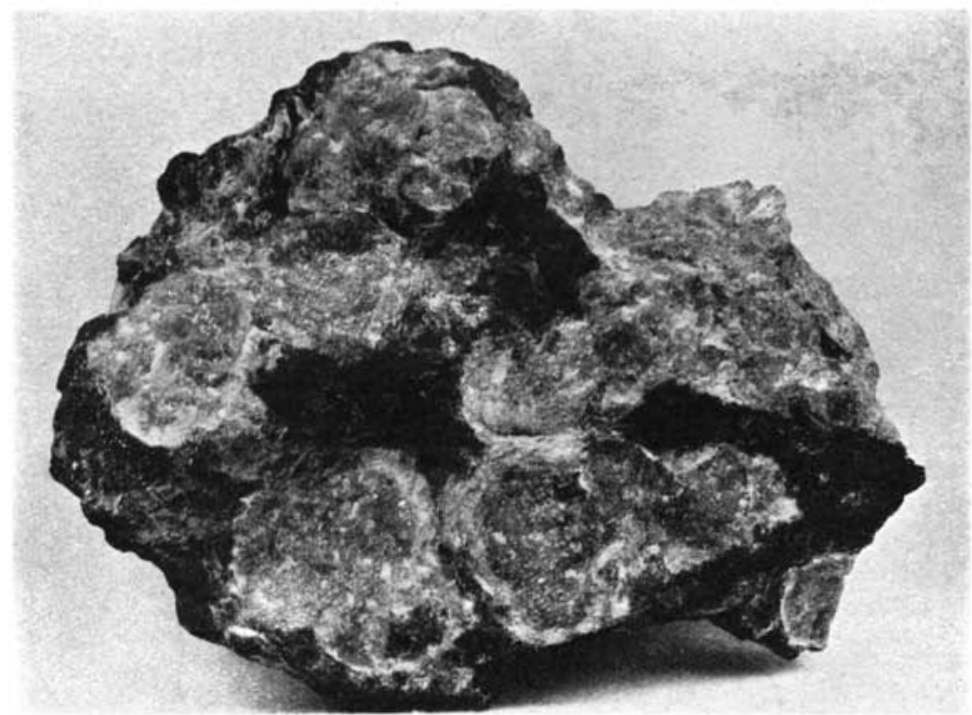

Fiti. 2 .

T. C. Day, Pholo. 


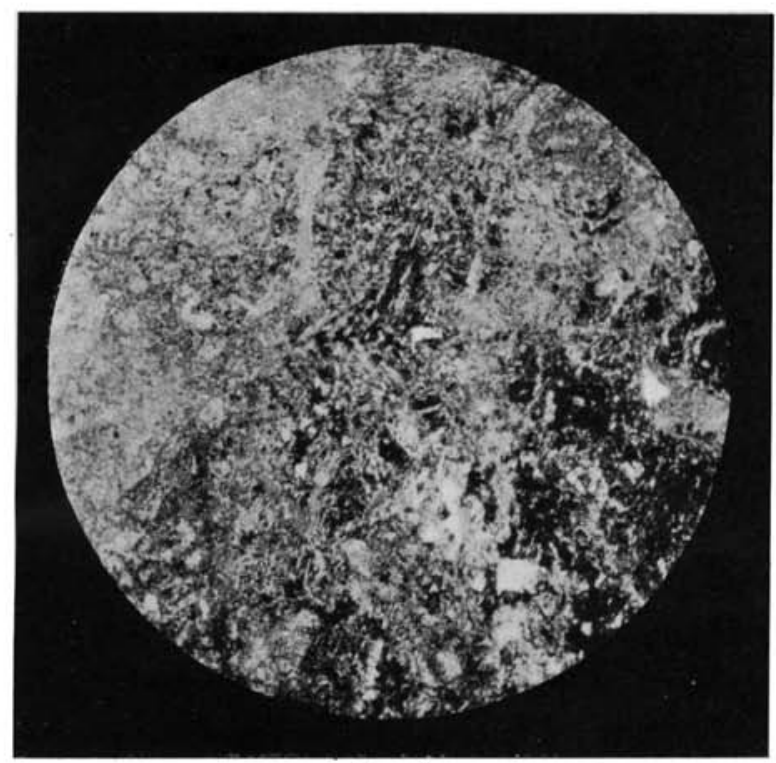

Fig. 1.

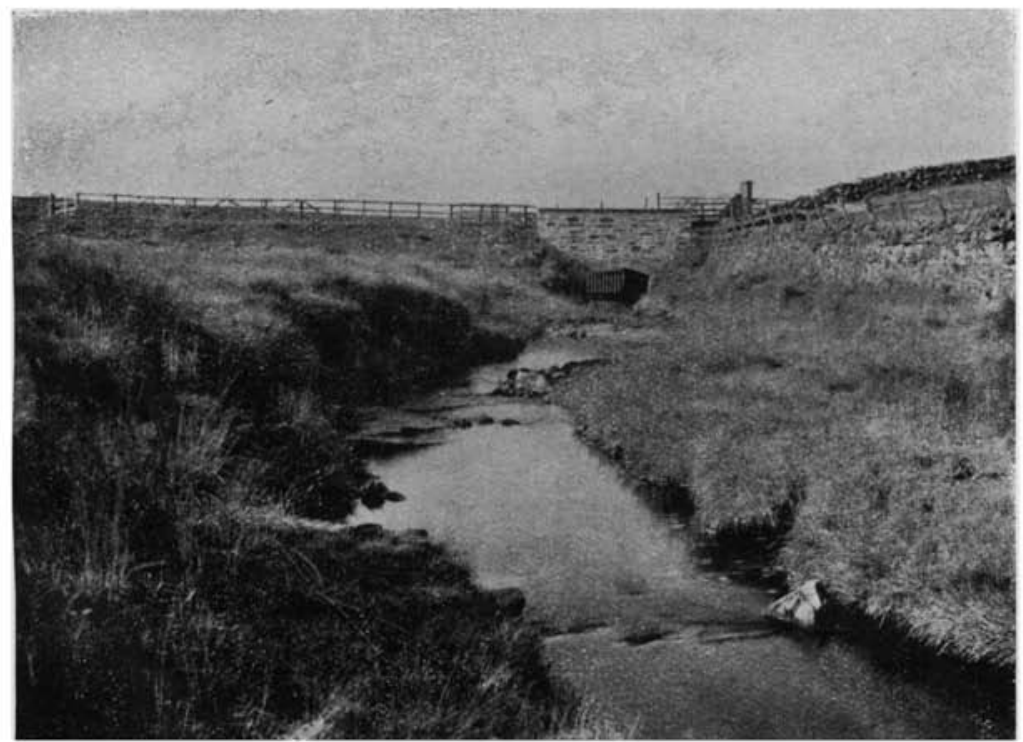

Fig. 2.

T. C. Day, Photo. 


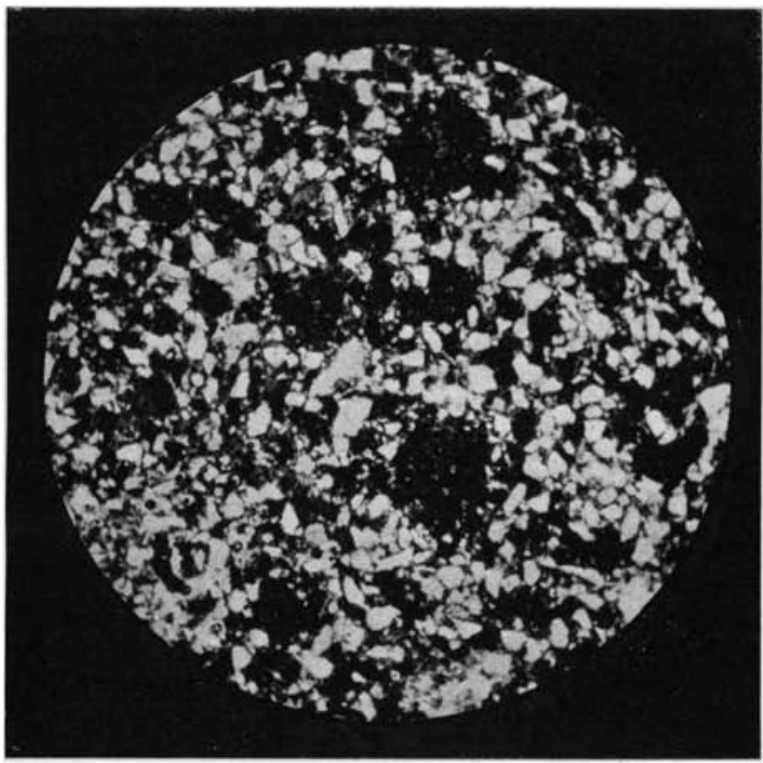

Fig. 1.

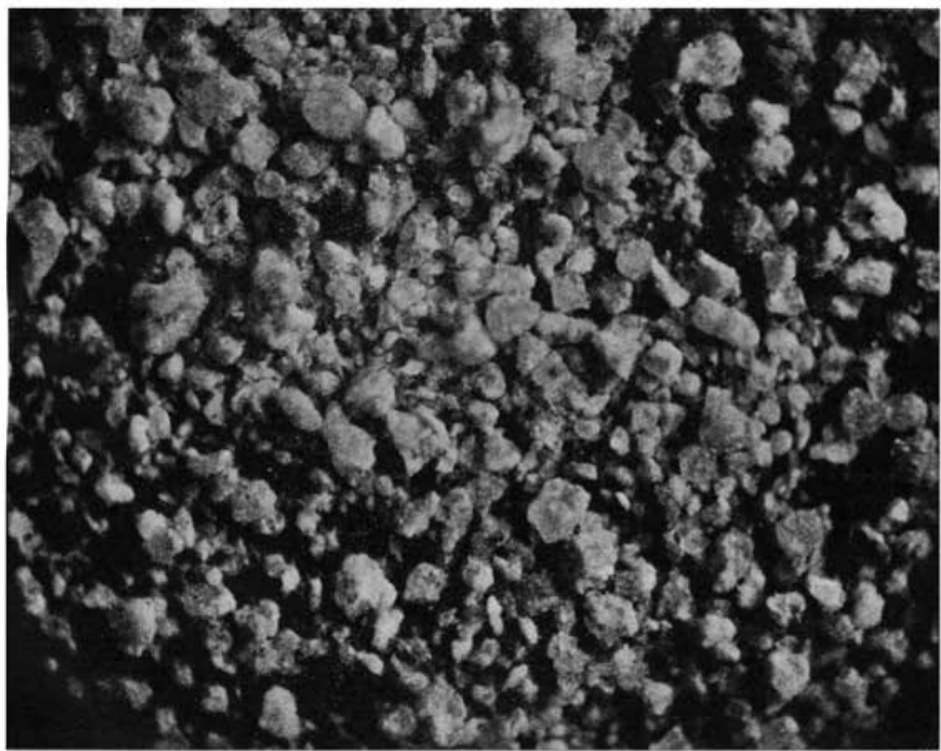

Fra. 2.

T. C. Day, Pholo. 
Downloaded from http://trned.lyellcollection.org/ at University of Georgia on June 21, 2015

Trans. Edin. Geot. Soc.

Vol. XI., Plate VI.

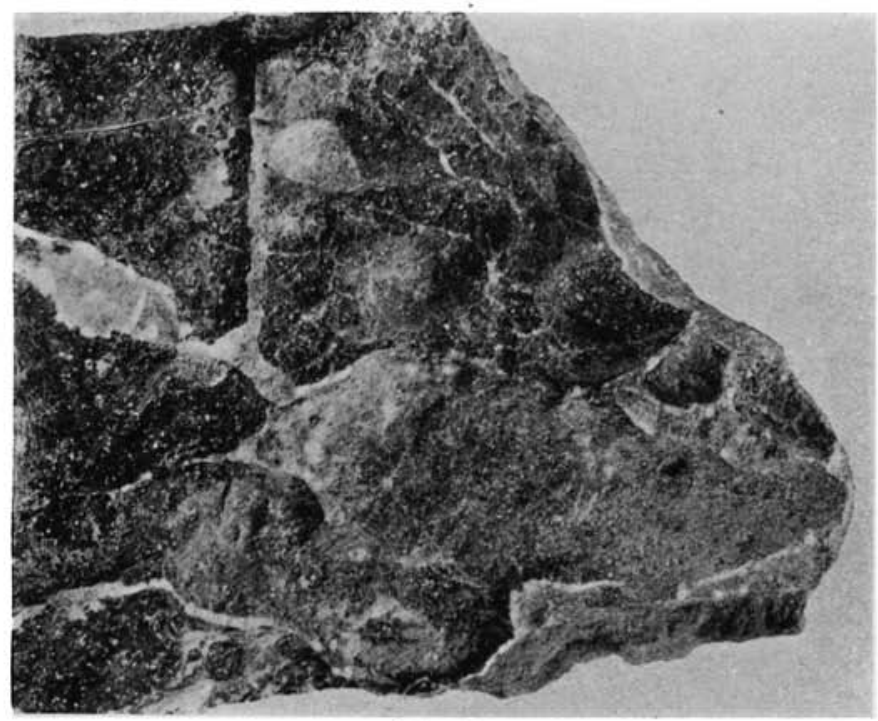

FIG. 1.

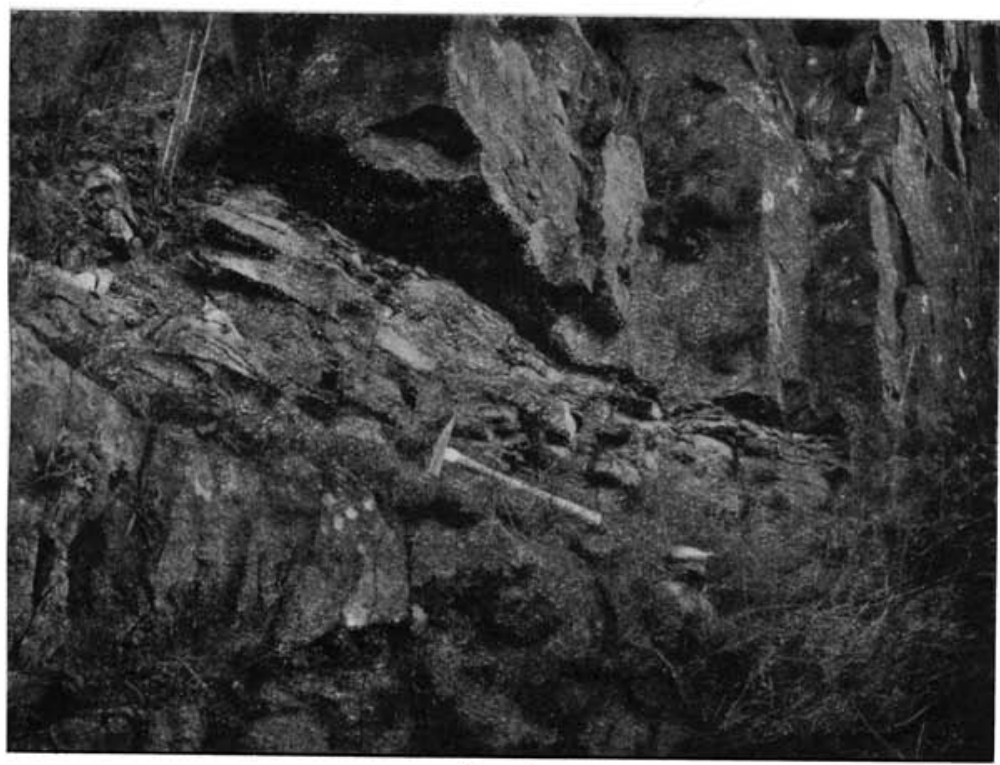

FIG. 2.

T. C. Day, Photo. 
IGNEOUS INTRUSIVE PHENOMENA AT UPPER WHITFIELD. 17

district may be seen. At Ravelrig, where an inferior contact of the sill is exposed, the dolerite is much weathered and decayed at the point of junction with the sedimentary rocks. But where it comes in contact with a band of sandstone, the contact surface of the latter is curiously moulded and puckered, and adhering to that surface is a thin black tachylite with pseudomorphs after felspar scattered through it (Plate VI, Fig. 1).

At Kaimes Hill quarry there may be seen, between two thick beds of sandstone, a band of much decomposed igneous rock (an offshoot of the olivine dolerite), and about one foot thick of such a peculiar structure that it might easily be taken for a band of shaly sediment. A close scrutiny, however, discloses its true nature, with the added evidence that the same kind of tachylite already mentioned is found adhering to the surfaces of the sandstone, above and below the band of decomposed igneous rock (Plate VI, Fig. 2).

\section{Platir III.}

\section{Explanatron of Plates.}

FIG. 1. Chert traversed by veins of intrusive basalt. The basalt is much decomposed, and has been largely replaced by calcite. $\times 12$.

Fic. 2. Hand specimen. Chert and dolomite altered by contact with intrusive basalt. The lighter spherulitic portions represent the dolomite. Natural size.

Piate IV.

Fra. 1. Basalt metasomatised by infiltration of dolomitic calcite. The remains of greatly decomposed basalt shown black. $\times 12$.

Fia. 2. View on the Cairn Burn, above the bridge, where the band of quartzite crosses the stream in the immediate foreground.

\section{Plate V.}

FIG. 1. Intrusive basalt, much decomposed, highly charged with sand grains. $\times 12$.

Fig. 2. Sand grains from the decomposed basalt, showing their etched surfaces. $\times 22$.

Prate VI.

Fra. 1. Black tachylite adhering to much grooved surface of sandstone. Ravelrig. $\times \frac{\text { e. }}{3}$

FIG. 2. Band of intrusive igneous rock (decomposed olivine dolerite) between beds of sandstone. Kaimes Hill. 